\title{
Study on Optimization of Gas Drainage Methods in High-burst Mines
}

\author{
Fengfeng Yang ${ }^{1 *}$,Dongfang Gao ${ }^{1}$, Jufeng Zhang ${ }^{1}$, Kezhen Zhao $^{1}$,Tai Xu ${ }^{1}$,Chao Zheng ${ }^{1}$,Liping Bai ${ }^{2}$ \\ ${ }^{1}$ School of Energy Engineering, LongDong University, 745000,China \\ ${ }^{2}$ Gansu Energy Qingyang Coal and Electricity Corporation Ltd., 745000, China
}

\begin{abstract}
After the mechanization upgrade of Yongjing Coal Mine, the original extraction method cannot solve the problem of gas. According to the actual production conditions of the mine, the source and composition ratio of gas emission are analyzed.By combining with the gas extraction method before upgrading and transformation, it is of great importance to determine the appropriate comprehensive gas extraction method and optimize the gas extraction parameters for improving the gas extraction effect and eliminating the risk of gas outburst.
\end{abstract}

\section{Introductions}

With the improvement of the mechanization level of coal mining, the speed of mine upgrading and transformation has accelerated. The depth of coal mining continues to expand, gas emission and gas pressure increase gradually, and gas control is more difficult ${ }^{[1-3]}$. Gas drainage is transformed from a single mode to a comprehensive extraction mode or a three-dimensional mode ${ }^{[4]}$. The original production capacity of Yongjing Coal Mine is $1.0 \mathrm{Mt} / \mathrm{a}$. Currently, $1.2 \mathrm{Mt} / \mathrm{a}$ mechanization upgrading is being carried out. The mine gas grade identification result is coal and gas outburst mine. Four gas explosion accidents have occurred since the construction of the well, and the gas poses a great threat to the safe production of the mine. In order to solve the problem of safe production, we began gas extraction in 1984 and established a permanent drainage system for the ground in Yongjing Coal Mine. The intensity of extraction and the scale of extraction are increasing year by year, and the effect of gas drainage is remarkable. With the mining of new mining areas, the scale of mine production is expanding continuously. At present, the mine is ready to carry out comprehensive mechanized coal mining upgrade and transformation, and the design of the gas extraction method after the $1.2 \mathrm{Mt} / \mathrm{a}$ mechanization upgrading of the mine is urgently needed for mine safety production.

\section{Mine situation}

The mine is mined in two levels, the No. 3 coal seam is level 1, No. 9 and No. 15 coal seams are level 2, and the service life of the first level is 11 years; the second level is 8 years; the mine service life is 19 years. A new fully mechanized mining face and two fully mechanized excavation working faces are arranged in each new and old mining areas. Coal dust is non-explosive, and the self-ignition tendency of coal is grade III, which is not easy to spontaneous combustion coal seam. The original gas pressure of coal seam is $1.14 \sim 2.37 \mathrm{MPa}$, the original gas content of coal seam is $14.5 \sim 20.89 \mathrm{~m}^{3} / \mathrm{t}$, and the permeability coefficient of coal seam is $3.25 \sim 5.78$ $\mathrm{m} 2 / \mathrm{MPa}^{2} \cdot \mathrm{d}$. The absolute gas emission rate of the mine is $158.04 \mathrm{~m}^{3} / \mathrm{min}$, and the relative gas emission rate is 53.86 $\mathrm{m}^{3} / \mathrm{t}$. The No.3 coal seam of shanxi group and the No.9 and No.15 coal seam of taiyuan group in the coal field are minable.

\section{Gas source and composition analysis}

The No. 3 coal seam of Yongjing Coal Mine is mined by layers, with the mining height of $2.96 \mathrm{~m}$. When mining on the upper stratified working face, because the lower stratified coal seam is directly exposed, the coal body gas desorption flows directly into the upper stratified working face, and when mining on the lower stratified working face, the gas emission from the working face will be relatively small. That is to say, the amount of gas emission is the largest when the upper working face is mined. Therefore, from the perspective of ventilation design and gas prevention, it is only necessary to predict the quantity of gas emission when the upper stratified working face is mined.

According to the prediction results of gas emission, the composition and proportion of each gas emission source in the mine are analyzed, as shown in Table 1 and Table 2.

\footnotetext{
* Corresponding author: Fengfeng Yang, 2356059065@qq.com
} 
Table 1 Prediction results of mine gas emission composition

\begin{tabular}{|c|c|c|c|c|c|c|}
\hline Mine & \multicolumn{2}{|c|}{ Heading Face } & \multicolumn{2}{c|}{ Working Face } & \multicolumn{2}{c|}{ Goaf } \\
\hline $\begin{array}{c}\text { Emission } \\
\text { Quantity } \\
\left(\mathrm{m}^{3} / \mathrm{min}\right)\end{array}$ & $\begin{array}{c}\text { Emission } \\
\text { Quantity } \\
\left(\mathrm{m}^{3} / \mathrm{min}\right)\end{array}$ & $\begin{array}{c}\text { Percentage } \\
(\%)\end{array}$ & $\begin{array}{c}\text { Emission } \\
\text { Quantity } \\
\left(\mathrm{m}^{3} / \mathrm{min}\right)\end{array}$ & $\begin{array}{c}\text { Percentage } \\
(\%)\end{array}$ & $\begin{array}{c}\text { Emission } \\
\text { Quantity } \\
\left(\mathrm{m}^{3} / \mathrm{min}\right)\end{array}$ & Percentage $(\%)$ \\
\hline 158.04 & 29.96 & 19 & 63.69 & 64.39 & 41 & 40 \\
\hline
\end{tabular}

Table 2 Prediction results of working face gas emission composition

\begin{tabular}{|c|c|c|c|c|}
\hline Working Face & \multicolumn{2}{|c|}{ Current Seam } & \multicolumn{2}{c|}{ Adjacent Seams } \\
\hline $\begin{array}{c}\text { Emission Quantity } \\
\left(\mathrm{m}^{3} / \mathrm{min}\right)\end{array}$ & $\begin{array}{c}\text { Emission Quantity } \\
\left(\mathrm{m}^{3} / \mathrm{min}\right)\end{array}$ & Percentage $(\%)$ & $\begin{array}{c}\text { Emission Quantity } \\
\left(\mathrm{m}^{3} / \mathrm{min}\right)\end{array}$ & $\begin{array}{c}\text { Percentage } \\
(\%)\end{array}$ \\
\hline 63.69 & 42.14 & 2.17 & 95 & 5 \\
\hline
\end{tabular}

According to Table 1 and Table 2, combined with mine exploitation and geological conditions, it can be concluded that Yongjing Coal Mine has many sources of gas emission, wide distribution range and complicated occurrence conditions of coal seam. Yongjing Coal Mine should adopt comprehensive extraction method combining various extraction methods for each gushing source to extract the gas from the working face, the heading face and the goaf.

\section{Optimization of the gas extraction method}

\subsection{Extraction of working face gas}

According to the prediction results of the source and composition of gas emission amount on the working face (Table 2), the gas on the working face comes partly from the coal wall of the mining layer and the gas desorbed by coal falling, and partly from the gas desorbed by coal dropping in the lower stratification and goaf. According to the permeability coefficient of coal seam and the attenuation coefficient of borehole gas flow, it can be known that the difficulty degree of gas extraction in No. 3 coal seam of Yongjing Coal Mine is extractable. Combined with the existing conditions of each coal seam and the gas source of Yongjing coal mine, and considering the amount of gas extraction required by the working face, the method of combining pre-extraction and simultaneous extraction is adopted to extract gas from this coal seam. In the working face, parallel boreholes along seam are drilled in double crossheading of working face, and the coal seam gas is pre-extracted before the working face is mined ${ }^{[5]}$. The pre-extraction time is more than 6 month, and "draining while mining" is carried out while mining. The schematic diagram of the drainage drilling arrangement is shown in Figure 1, and the drilling parameters are shown in Table 3.

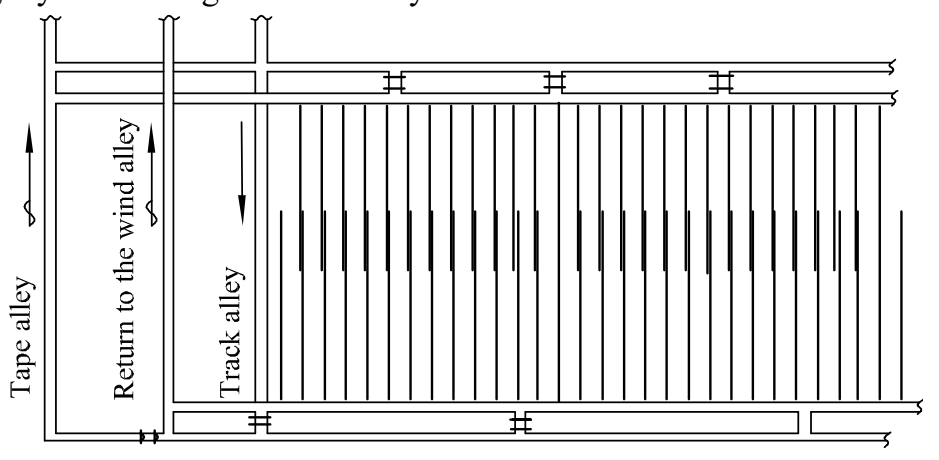

Fig.1 Layout diagram of gas extraction boreholes along the seam in working face

Table 3 Parameter table of parallel drilling

\begin{tabular}{|c|c|c|c|c|}
\hline $\begin{array}{c}\text { The angle between the } \\
\text { drilling and the roadway }\left(^{\circ}\right)\end{array}$ & $\begin{array}{c}\text { The angle between the drilling and } \\
\text { the horizontal plane }\left({ }^{\circ}\right)\end{array}$ & $\begin{array}{c}\text { Hole } \\
\text { depth }(\mathrm{m})\end{array}$ & $\begin{array}{c}\text { Drilling hole } \\
\text { diameter } \\
(\mathrm{mm})\end{array}$ & $\begin{array}{c}\text { Distance between } \\
\text { holes }(\mathrm{m})\end{array}$ \\
\hline 90 & Same as coal seam dip Angle & 85 & 89 & 8 \\
\hline
\end{tabular}

\subsection{Gas extraction of heading face}

In order to eliminate the outburst risk of coal body in front and on both sides, the method of "gas drainage first then digging" in heading face is adopted. During the roadway excavation process, the drilling site is constructed on both sides of the roadway, and the drilling holes are arranged in the drilling field and the communication lane for extraction. The drill field is $3.5 \mathrm{~m}$ long and $4 \mathrm{~m}$ deep, and the height is the same as that of the roadway. The drilling layout of the tunneling working face should be at least $120 \mathrm{~m}$ ahead of the roadway working face and ensure the 
pre-pumping time. The parameters of the extraction drilling selected based on this are shown in table 3 , and the drilling layout is shown in figure 2.

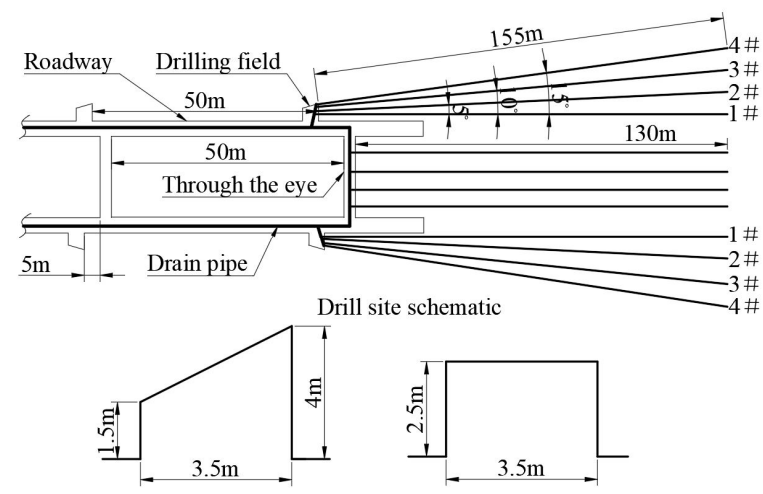

Fig. 2 Schematic diagram of gas drainage drilling arrangement in heading face

Table 4 Table of parameters of drilling while digging and draining

\subsection{Extraction of semi-enclosed goaf}

Due to the communication between the semi-enclosed goaf and the ventilation network of the working face, under the pressure difference, the gas in the goaf may flow into the upper corner and the gas overrun occurs. At the beginning of the working face mining, the gas emission from the goaf will not affect the normal production of the mine in the initial period. However, with the extension of the mining time and the expansion of the mining area, the large amount of gas from the goaf will undoubtedly aggravate the ventilation burden of mine, therefore the following extraction scheme is put forward and optimized.

\subsubsection{Scheme design}

Option 1: Gas extraction method of upper drilling hole on return air roadway

The drilling site in the return airway of the working face is constructed, and the drilling hole above the landing arch of the goaf is constructed,so that the bottom of the hole is above the initial arching arch, capturing the gas in the collapse zone, the method can also take into account the gas accumulation in the adjacent layers of gas and the goaf $^{[6]}$. The drill field spacing is about $40 \mathrm{~m}$, and 3 to 5 holes are arranged in each drill field. The drilling layout is shown in figure 2.

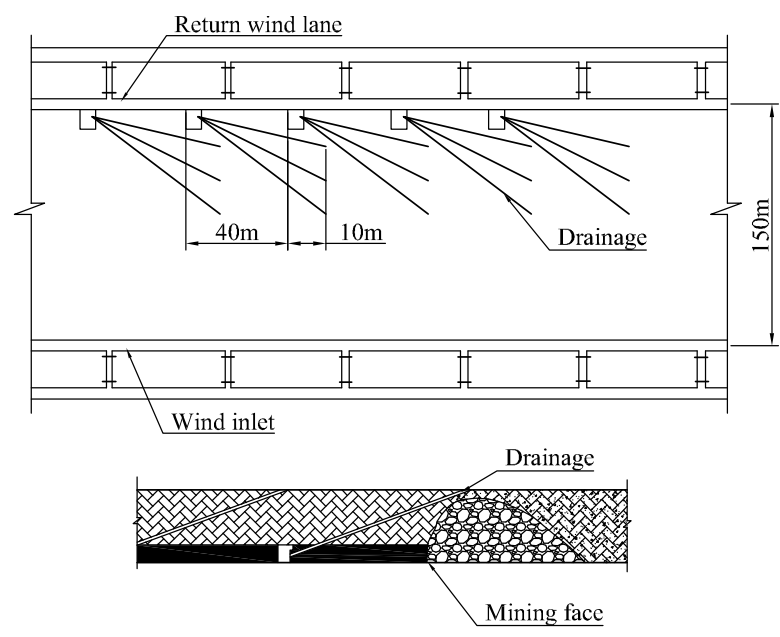

Fig.3 Gas extraction scheme of upper drilling hole on return air roadway

Option 2: Method of buried pipe in the goaf

Before the roof falls, the pumping pipe is directly embedded or built in the goaf for gas drainage. In order to improve the pumping effect, we construct a small hole on the pipe wall of the pumping pipe, and the pumping pipe is made as far as possible in the area with higher

\begin{tabular}{|c|c|c|c|c|}
\hline \multicolumn{2}{|c|}{$\begin{array}{l}\text { The angle between } \\
\text { the drilling and the } \\
\text { roadway }\left(^{\circ}\right)\end{array}$} & $\begin{array}{c}\text { Drilling } \\
\text { elevation }\left(^{\circ}\right)\end{array}$ & $\begin{array}{l}\text { Hole } \\
\text { depth } \\
\text { (m) }\end{array}$ & $\begin{array}{c}\text { Drilling } \\
\text { hole } \\
\text { diameter } \\
(\mathrm{mm})\end{array}$ \\
\hline $1 \#$ & 0 & \multirow{4}{*}{$\begin{array}{c}\text { Nearly } \\
\text { horizontal }\end{array}$} & \multirow{4}{*}{155} & \multirow{4}{*}{89} \\
\hline 2\# & 5 & & & \\
\hline 3\# & 10 & & & \\
\hline 4\# & 15 & & & \\
\hline $\begin{array}{c}\text { Interstitical } \\
\text { hole }\end{array}$ & 0 & $\begin{array}{c}\text { Nearly } \\
\text { horizontal }\end{array}$ & 130 & 89 \\
\hline
\end{tabular}

concentration at the top of the coal seam ${ }^{[5]}$. The method of buried pipe in the goaf is shown in Figure 4.

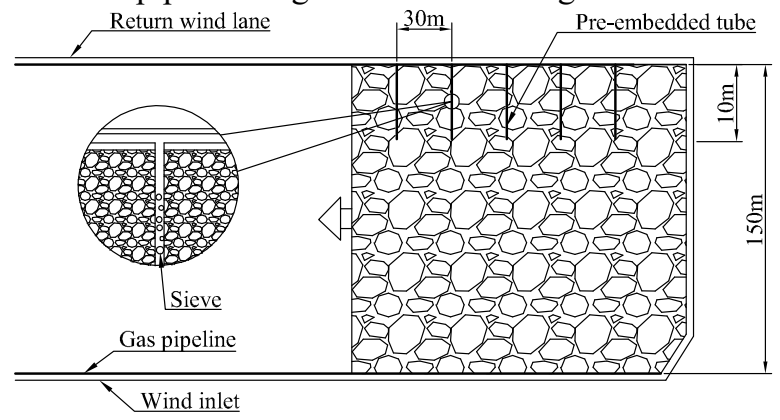

Fig.4 Semi-enclosed goaf tube extraction scheme

Option 3: Gas extraction in goaf by closed tail roadway

The means of intubation in closed tail lane is used to extract the gas in the goaf. As the work advances, the seal will migrate. The layout of the roadway and pipeline is shown in Figure 5. The closed wall should be as close as possible to the contact lane. The closed wall is preferably filled with loess in the middle of two layers of brick walls, which has good airtightness. According to the extraction situation, the extraction parameters such as concentration, negative pressure and flow rate can be adjusted through 
the valve during the extraction process. The management of the communication lane should be strengthened during the extraction process.

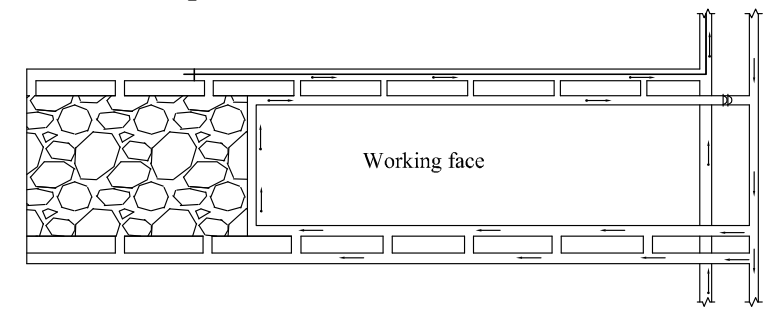

Figure 5 Schematic diagram of working face goaf extraction system

\subsubsection{Scheme optimization}

(1) Advantages of the scheme 1: (1)The effect of gas extraction is good. (2)The construction of drilling field and drilling hole is synchronized with the tunneling of working face crossheading. (3)The extraction and production do not affect each other;

Disadvantages: (1)Need to construct drilling field and drilling, which increases the extraction cost. (2) Ventilation management in the drilling site is difficult, prone to gas accumulation. (3)Direct coal wall construction in the return air tunnel is prone to air leakage, which increases the difficulty of ventilation safety management.

(2) Advantages of scheme 2: (1)The construction is simple. (2)The service space for extraction is longer than of scheme 1. (3)The effective extraction distance for the goaf is long. (4)The engineering quantity of drainage is less than that of scheme 1.

Disadvantages: (1)Lost pipe in the goaf cannot be recovered, so the investment cost is large. (2)the extraction effect is not as good as scheme 1.(3)Extraction management is difficult.

(3) Advantages of scheme 3: 1)can achieve better gas drainage effect.(2)extraction technology and construction is simple.(3)no need to set up special drilling field and drilling. (4) is not easy to leak.

Disadvantages: (1)increase ventilation management issues. (2) need to construct a closed wall.

Through the comparison of the above several schemes, the scheme 3 is selected, that is, the method of extracting the gas in the goaf by closed tail lane, which is simple and has a good effect. Combining the gas drainage in the lower adjacent layer for extraction, the method not only can extract the gas in the falling zone of the goaf, but also can take into account the gas accumulation in the gas and goaf in the adjacent layer under the extraction.

\subsection{Fully enclosed goaf extraction}

In order to prevent the outflow of gas from the goaf, we should seal the finished working face without delay; During the construction of the closed wall, gas extraction shall be carried out by intubating into the closed wall of the goaf in advance, as shown in Figure 6.
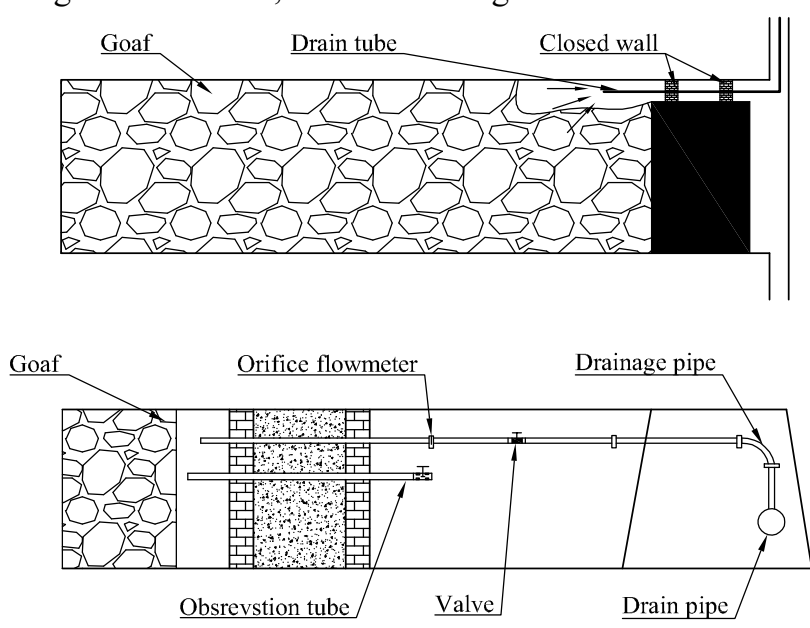

Figure 6 Schematic diagram of gas drainage in fully enclosed mining area

\section{Conclusions}

After analysis of the source and composition ratio of gas emission according the prediction result of gas emission from the working face and comprehensive consideration of drainage management and other factors, "parallel boreholes along seam" is selected to extract gas from the working face, "gas drainage first then digging" method is adopted to extract gas from the working face, and "closed tail roadwa" + "enclosed goaf" method is adopted to extract gas from the goaf area, and reasonable parameters of gas extraction drilling are determined.

\section{Acknowledgments}

This work was financially supported by china science industry-university-research innovation consortium project (ZLGC201902-13),youth fund of Gansu province (18JR3RM240), science and technology research project(MTKJ2018-277,MTKJ 2018-279),

youth science and technology innovation project of Long Dong college (XYZK1702), and research projects of safety production in Gansu province (GAJ00004,GAJ00011).

\section{References}

1. Baobin Gao, Zuguang Wang, Junjie Chang. Applica-tion research of gas drainage technology in externally wrong-type highdrainage roadway[J]. Journal of Safety Science and Technology,11(2015)

2. Yuanping Cheng, Lei Wang, Xiaolei Zhang.Environ-mental impact of coal mine methane emissions and responding strategies in China[J].International Journal of Greenhouse Gas Control,5 (2011)

3. Liang Yuan.Research on comprehensive mine gas prevention and control technology system in mine 
with complicated geological conditions[J].Coal Science and Technology,34(2006)

4. Hong Li,Mingju Liu,Hong Gao.Technology of gas extraction in working face with large mining height of high outburst mine and its practice[J].Journal of Safety Science and Technology,15 (2019)
5. Jun Liu,Yong Zhao.Study on Gas-control of the 1206 Fully Mechanized Coal Face in Sima Coal Mine[J].Coal Engineering,51(2019)

6. Huijie Bi,Zhigang Deng,Shankun Zhao, et al.Research on gas drainage technology of directional high-level borehole in high gassy fully-mechanized mining face[J].Coal Science and Technology,47(2019) 